\title{
UNIVERSIDADE COMUNITÁRIA E AVALIAÇÃO INSTITUCIONAL: O CASO DAS UNIVERSIDADES COMUNITÁRIAS GAÚCHAS
}

\author{
Rafael Ângelo Bunhi Pinto*
}

Recebido em: 08 de agosto de 2008 Aprovado em: 18 de setembro de 2008

* Assessor Acadêmico da Universidade de Sorocaba - Uniso. Mestre em Educação pela mesma Universidade. E-mail: rafael.pinto@uniso.br

Resumo: A década de 1980 marcou uma série de transformações na educação superior, dando início aos debates sobre um novo modelo de instituição de educação superior - a universidade comunitária - e, também, de uma cultura avaliativa em nosso país. Nas décadas seguintes, esse modelo de instituição buscou seu fortalecimento no país, mostrando suas características primordiais e suas diferenças em relação àquelas mantidas pelo poder público e, também, àquelas instituições estritamente privadas. Essas Instituições se desenvolveram em várias regiões, com ênfase no sul do país, onde criaram o Consórcio das Universidades Comunitárias Gaúchas - COMUNG. As Instituições participantes desse consórcio, dentre outras atividades, desenvolveram um mecanismo próprio de avaliação, que se preocupou com o (re)pensar de suas atividades de ensino, pesquisa, extensão e gestão. O objetivo desta pesquisa será buscar respostas ao entendimento da avaliação institucional pelas Universidades Comunitárias gaúchas e verificar como a questão da responsabilidade social se insere em seu processo de avaliação. Também, objetivará estudar os processos históricos e as necessidades de adaptações que se fizeram necessárias quando da criação do Sistema Nacional de Avaliação da Educação Superior - SINAES.

Palavras chave: Educação superior. Brasil. Universidade comunitária. Universidades comunitárias gaúchas. Educação superior. Avaliação. Universidades. Responsabilidade social.

\section{THE COMMUNITY UNIVERSITY AND ITS INSTITUTIONAL EVALUATION: A CASE STUDY OF THE COMMUNITY UNIVERSITIES OF THE STATE OF RIO GRANDE DO SUL BRAZIL}

Abstract: In the 1980s higher education experienced a series of transformations, commencing the debates about a new model of higher education institutions - the community university - and also of an evaluative culture in Brazil. During the following decades, this model of institution tried to strengthen its bases in the higher education scenario of the country, showing its primary characteristics and its differences from the public and the private branches of higher education. These universities were instituted in various regions of the country with emphasis in the southern region, where a Consortium of the Gaucho Community Universities (COMUNG) was created. They also developed their own mechanism of evaluation, with concerns about (re)thinking its teaching, research, extension and management methods. The purpose of this research is to achieve an understanding of the institutional evaluation system in community universities in southern Brazil and to verify how social responsibility is inserted in the evaluation process. It also studies the historical and cultural processes and the adaptations that were necessary when the National Higher Education Evaluation System (SINAES) was created.

Key words: Higher education. Brazil. Community university. Community universities from southern Brazil. Higher education. Evaluation. Universities. Social responsibility. 


\section{Introdução}

A década de 1980 pode ser definida como uma época que apresentou transformações significativas no mundo e, no caso do estudo ora apresentado, na educação mundial e na brasileira. Essas transformações mundiais surtiram efeito nos contextos político, econômico e social, marcadas, principalmente, pela expansão da economia globalizada e da ideologia neoliberal.

No Brasil, entre o final dessa década e início da década de 1990, houve um aumento de investimento do setor privado na educação superior e, por parte dos governos federal e estaduais, diminuição de recursos em termos de investimento para a educação pública. O Estado do bem-estar social tornou-se, a partir de então, um Estado avaliador, condicionando o financiamento para as universidades à demonstração de seu desempenho acadêmico, institucional e produtivo.

Ainda no contexto mundial, nesse período cresce, também, a ênfase dada às questões referentes à avaliação da educação superior, principalmente nos Estados Unidos e em alguns países da Europa, no marco de um processo global de crise e retração de investimentos destinados às suas políticas públicas. A liberação de recursos para serviços públicos às instituições de ensino superior desses países ficou condicionada à avaliação de sua qualidade. Também na América Latina, a avaliação ganha, progressivamente, maior sentido e importância, constituindo-se em planejado dispositivo de controle e regulação social. Em nosso país, tendo em vista o crescimento de instituições de ensino superior, a partir de 1990, um contexto avaliativo começa a se consolidar, sendo possível observar tanto uma produção intelectual ampliada sobre a temática, quanto a gestação e implementação de propostas e políticas de âmbito mais geral. Diversos segmentos da sociedade, principalmente a mídia, passam a exercer pressões no sentido de as instituições de ensino superior prestarem contas da qualidade de seus cursos, serviços e dos recursos nelas alocados.

Esse cenário é também marcado pelo fortalecimento de um movimento, iniciado na década de 1980, em favor das Universidades Comunitárias (VANNUCCHI, 2004, p. 11) que, mesmo estando caracterizadas, dentro de sua natureza jurídica, como instituições de educação superior privadas, apresentam forte apelo social no ensino, na pesquisa e na extensão, voltado para a comunidade. Essas instituições existem em vários estados do Brasil, com uma forte atuação, no entanto, no sul do país.

Assim, o artigo proposto mostrará o resultado de pesquisa realizada com algumas dessas instituições comunitárias gaúchas, com respostas para as seguintes indagações: Como as Universidades Comunitárias gaúchas entendem 
a avaliação institucional (interna e externa) e como a responsabilidade social dessas instituições se insere em seu processo de avaliação? Qual a cultura de avaliação que possuem e qual a contribuição histórica que deram para os processos e sistema de avaliação atualmente existente? O Sistema Nacional de Avaliação da Educação Superior - SINAES representa algo de novo para as universidades comunitárias?

\section{A Universidade Comunitária: um Modelo em Construção}

Até a metade da década de 1960, a educação superior brasileira era formada, basicamente, por instituições públicas e instituições confessionais; essas últimas muito mais preocupadas com suas ideologias de caráter religioso e suas visões de mundo na educação do que com a transformação desse bem público em algo lucrativo.

A expansão da educação superior nas décadas seguintes teve como uma das grandes questões de pano de fundo o financiamento das universidades não públicas, especialmente no que se refere às confessionais que, até a década de 1970, recebiam verbas governamentais para o desenvolvimento de suas atividades. Essas instituições, por terem ideologias diferentes, não queriam ser equiparadas às outras Instituições de Ensino Superior - IES do setor privado, surgindo a necessidade de unirem forças em torno de seus interesses, objetivos e princípios comuns.

Assim, no início da década de 1980, alguns segmentos da sociedade civil iniciaram um movimento de apoio às instituições comunitárias. Em 1985, mais precisamente, foi aprovado um manifesto em prol dessas IES em reunião realizada pelo Conselho de Reitores das Universidades Brasileiras - CRUB, para que elas recebessem verbas do governo para desenvolvimento de suas atividades educacionais. No mesmo ano, o grupo que estudava a reformulação da educação superior no país frisou, em seu Relatório Final, que era papel do Estado "garantir a liberdade de ensino em todos os seus aspectos e apoiar, financeiramente, as iniciativas educacionais de origem privada ou comunitária, de inegável interesse público e relevância social” (BRASIL, 1985, p. 4). Esse grupo alertou para o fato de que as verbas deveriam ser destinadas somente às instituições com comprovada qualidade e que as atividades desenvolvidas por elas tivessem retorno para a comunidade.

Já em 1988, reitores de vinte universidades ${ }^{1}$ se reúnem para debater sobre seus ideais comuns e, também, influenciar o Congresso Nacional a incluir o

1 Dessas universidades, dezessete apresentavam caráter confessional (dezesseis católicas e apenas uma instituição metodista). As outras três universidades eram laicas, localizadas no Rio Grande do Sul. 
termo "escolas comunitárias" no texto que daria origem, posteriormente, à nova Constituição do Brasil. Essa articulação foi de extrema importância para essas instituições, tendo em vista que, nesse período, se estendendo até meados da década de 1990, o setor privado vivia momento de grande expansão na educação superior e objetivava ter acesso às verbas governamentais destinadas à educação. Esse crescimento culminou com um grande número de universidades que foram reconhecidas nesse período, principalmente aquelas pertencentes ao segmento estritamente particular (ou empresarial). Durham (apud BITTAR, 2001, p. 35), ao tratar dessa expansão do ensino privado, apresenta a diversificação existente entre as IES desse segmento, ressaltando que:

o setor privado, além de ter expandido, também se diversificou internamente nas décadas subseqüentes à reforma. No período anterior era constituído majoritariamente por instituições não lucrativas, em geral confessionais ou criadas por iniciativa das comunidades locais. Parte destes estabelecimentos foi estadualizada ou federalizada. Mas, paralelamente, desenvolveram-se novas instituições comunitárias, mantidas pela Igreja ou por iniciativas laicas, envolvendo prefeituras e entidades representativas da sociedade civil que constituem, no conjunto, um subsistema que se poderia denominar público não estatal.

Após a aprovação do texto constitucional, com a inserção do termo "escolas comunitárias”, aconteceu, em 1991, o $1^{\circ}$ Fórum de Reitores das Universidades Comunitárias do Brasil (antes mesmo do surgimento de uma Associação que as representasse). Quatro anos mais tarde, em janeiro de 1995, surge, então, a Associação Brasileira das Universidades Comunitárias - ABRUC, associação civil, sem fins lucrativos, com o objetivo de promover, consolidar e defender o conceito de Universidade Comunitária (e, mais tarde, também de Centros Universitários Comunitários).

No mesmo ano de sua criação, essa Associação promoveu o $1^{\circ}$ Seminário Nacional das Universidades Comunitárias, com o intuito de consolidar a utilização do termo “comunitário” entre as Instituições de Ensino Superior. No $2^{\circ}$ Seminário Nacional das Universidades Comunitárias, em 1996, com vinte e oito universidades afiliadas, a ABRUC deu continuidade aos debates sobre a temática desse conceito.

Assim, em 1996, o termo "comunitário" também é incluído no texto da nova Lei de Diretrizes e Bases da Educação Nacional - LDBEN (Lei nº 9.394/96). Ao tratar da categorização das IES privadas, em seu art. 20, a referida Lei estabelece uma diferenciação entre as instituições “comunitárias” e as “con- 
fessionais", afirmando que as primeiras "são instituídas por grupos de pessoas físicas ou por uma ou mais pessoas jurídicas, inclusive cooperativas de pais, professores e alunos, que incluam em sua entidade mantenedora representantes da comunidade", enquanto que as segundas "são instituídas por grupos de pessoas físicas ou por uma ou mais pessoas jurídicas que atendem a orientação confessional e ideologia específicas" e, também, aquilo que é peculiar das instituições comunitárias acima citadas. (BRASIL, 1996)

Verifica-se, nesse contexto, que a separação entre o confessional e o comunitário existente na LDBEN traz à tona a idéia de que o primeiro termo, por si só, não contém a característica de comunitário, pois as instituições caracterizadas apenas como confessionais nascem com base em doutrinas religiosas. Já a natureza comunitária precisa ser construída e reconstruída, ficando clara, no texto legal, a necessidade de participação da sociedade nesse processo e na tomada de decisões. No entanto, pode-se fazer uma combinação entre esses tipos de instituições sem descaracterizá-las, ou seja, os termos podem se unir para melhor definir ou caracterizar uma IES, como a própria Lei estabelece.

Ao tratar dessa questão, Vannucchi $(2004$, p. 22) afirma que o texto legal da LDBEN “define as universidades comunitárias pelo seu poder instituidor ('são instituídas por grupos de pessoas físicas ou por uma ou mais pessoas jurídicas') e pela exigência de representação indireta ("que incluam na sua mantenedora representantes da comunidade')".

Um dos primeiros grandes desafios enfrentados pela ABRUC ocorreu no ano de 1997, com a promulgação do Decreto ${ }^{\circ}$ 2.207/97, quando essa Associação mobilizou-se, por meio de várias reuniões com dirigentes de suas instituições afiliadas, para um debate sobre o conteúdo do texto desse decreto. As discussões e críticas a esse decreto eram feitas, principalmente, em relação à questão da participação acadêmica no conselho fiscal das mantenedoras e à aplicação de parte da sua receita operacional para o pagamento de pessoal docente e técnico-administrativo. Essa característica divergia do que era praticado pelas instituições de propriedade patrimonial privada, ressaltando, ainda, as diferenças entre as organizações confessionais e comunitárias. O texto legal era visto como preocupante e com certo exagero, o que não justificava essa espécie de intervenção nas organizações por parte do Estado. O decreto levava a discussão de práticas financeiras, dando mais ênfase a esse procedimento do que ao debate da qualidade da educação no país.

As reflexões e críticas que surgiram com o debate relacionado ao Decreto $n^{0} 2.207 / 97$ levaram à sua revogação e à sua substituição, pelo Decreto $n^{\circ}$ 
2.306/97, revogado, posteriormente, pelo Decreto $n^{0} 3.860 / 2001^{2}$. Para Frantz (2006, p. 134):

A sucessão de três decretos sobre o mesmo assunto, em tão pouco tempo, não deixa de ser reveladora dos diferentes interesses e forças presentes no espaço do ensino superior brasileiro e das dificuldades políticas para acomodar tal quadro de interesses e forças. Os decretos, dentre suas normas legais para dar conta da situação, procuram atribuir responsabilidades às entidades mantenedoras de ensino superior sem fins lucrativos, dentre elas, as universidades comunitárias.

Pelo exposto, percebe-se que desde as lutas do período constitucional da década de 1980, já existia uma identidade e uma aliança entre as iniciativas confessionais e laicas (ou não confessionais), o que permitiu a criação da ABRUC. Assim, pode-se dizer que todos os movimentos então realizados se relacionavam como um grande esforço para a construção de um instrumento comum de representatividade nos órgãos públicos da área de educação superior, mais até do que uma parceria comum a respeito de uma universidade comunitária. Trabalhou-se, então, na construção e organização de uma Associação com semelhanças e interesses comuns, independentemente de serem confessionais ou laicas. (FRANTZ, 2002, p. 24)

O adjetivo comunitário deriva-se de comunidade e, assim sendo, o termo, para definir uma universidade, pode ser utilizado tanto pelas instituições confessionais quanto pelas instituições laicas, pertencentes a outras ramificações institucionais nascidas das chamadas comunidades regionais, não geridas e/ou mantidas pelo Estado, sem vínculo com igrejas (ou congregações religiosas) e organizações privadas. O termo comunitário pode ser utilizado levando-se em consideração tanto a natureza jurídica da mantenedora (fundação ou associação) quanto a iniciativa organizacional que inspira a missão da universidade (laica ou confessional).

No caso das universidades confessionais, verifica-se que elas estão muito mais ligadas aos interesses de seus criadores, congregados numa mesma ideologia e lutando pela mesma fé, valores morais e religiosos, com o intuito de imbuir esses princípios na educação que oferecem à sociedade. Essas instituições são mantidas juridicamente, em sua maioria, por igrejas ou congregações, cujos integrantes fazem parte do corpo dirigente da Instituição que mantém ou de seu

2 O Decreto $^{\circ}$ 3.860/2001 foi revogado pelo Decreto $n^{\circ}$ 5.773/2006, que dispõe sobre o exercício das funções de regulação, supervisão e avaliação de instituições de educação superior e cursos superiores de graduação e seqüenciais no sistema federal de ensino. É importante destacar que, tanto um quanto o outro, quase não abordam as questões polêmicas que existiam no Decreto $n^{\circ}$ 2.207/97. 
Conselho Universitário. Muitas delas também possuem grande experiência na área educacional voltada para a educação infantil, ensino fundamental e ensino médio, além de possuírem organização administrativa semelhante à estrutura organizacional da igreja a que estão diretamente vinculadas.

Já as universidades laicas, expressam mais o sentido de instituições criadas pela própria comunidade em que estão inseridas ou pela sociedade civil de uma cidade ou região. Sem alinhamento político ou ideológico de qualquer natureza, têm o intuito de implementar um projeto de educação que atenda aos apelos e necessidades do local onde estão inseridas. Os representantes da sociedade civil que contribuíram para sua criação e organização, geralmente possuem participação nos órgãos colegiados / conselhos superiores da instituição, contribuindo para a tomada de decisões e colaborando na gestão institucional. Também há, na maioria delas, participação do poder público local ou regional nos conselhos superiores.

Atualmente, chegam a 54 o número de Instituições de Ensino Superior afiliadas à ABRUC, distribuídas entre 12 estados brasileiros, conforme se pode verificar na Tabela 1.

Tabela 1 - № de IES, por Estado, afiliadas à ABRUC

\begin{tabular}{|l|c|}
\hline \multicolumn{1}{|c|}{ Estado } & Total \\
\hline São Paulo & 17 \\
\hline Rio Grande do Sul & 14 \\
\hline Santa Catarina & 06 \\
\hline Rio de Janeiro & 04 \\
\hline Minas Gerais & 04 \\
\hline Paraná & 03 \\
\hline Goiás & 01 \\
\hline Bahia & 01 \\
\hline Pernambuco & 01 \\
\hline Paraíba & 01 \\
\hline Distrito Federal & 01 \\
\hline Mato Grosso do Sul & 01 \\
\hline Total & 54 \\
\hline
\end{tabular}

Pode-se dizer que, dentre os Estados com o maior número de IES Comunitárias, há duas características bem marcantes: no Estado de São Paulo, há a predominância de instituições comunitárias confessionais, mantidas ou com intervenção das igrejas católica e metodista em suas atividades. Já no Estado do Rio Grande do Sul, há a predominância de instituições laicas, não confessionais, criadas e geridas por comunidades locais para atender às suas necessidades que 
se aglutinaram, em sua maioria, no Consórcio das Universidades Comunitárias Gaúchas - COMUNG.

\subsection{O Consórcio das Universidades Comunitárias Gaúchas - COMUNG}

O Estado do Rio Grande do Sul caracteriza-se, dentro do sistema brasileiro de ensino superior, pela existência de um número significativo de universidades comunitárias, ao lado de universidades federais, estaduais e estritamente particulares. Para Marques (apud FRANTZ, 2006, p. 151), um dos idealizadores da concepção de universidades comunitárias e conhecedor de seu processo histórico, o desenvolvimento dessas instituições no Rio Grande do Sul

[...] se enraíza numa tradição de escola mantida pelas comunidades
rurais [...] brotando de uma prática social sedimentada no decorrer de
mais de um século: desde as pequenas escolas rurais desamparadas
de qualquer apoio do poder governamental até o surgimento de uma
camada de intelectuais oriundos daquelas comunidades e escolas e de
uma forte demanda de educação superior por parte de contingentes
crescentes de jovens também procedentes daquelas comunidades ou
de pequenas cidades que no meio delas se formaram.

Verifica-se, portanto, que, no Rio Grande do Sul, as instituições comunitárias, em sua maioria, nasceram em espaços onde houve ausência do Estado na educação superior. Nascem da mobilização e do esforço da sociedade civil, diferenciando-se das experiências confessionais ou particulares. Nesse sentido, Frantz (2006, p. 151) também afirma que "junto a essas populações, a noção de organização comunitária passa pela organização da educação como atividade das comunidades e não do Estado”. Essas instituições são enraizadas na história da colonização e da organização social dos imigrantes e seus descendentes.

Segundo Morosini (2006, p. 291), o movimento que originou o COMUNG se iniciou no ano de 1990, quando alguns reitores das universidades que hoje fazem parte desse consórcio organizaram o Programa Interinstitucional de Integração da Universidade com a Educação Fundamental (hoje denominado PIEB, voltado para a Educação Básica). Esse programa tinha uma forte atuação no Distrito Geoeducacional 38 - DGE38 e estabelecia como metas nas ações conjuntas entre aquelas universidades a participação efetiva e integrada em projetos nacionais de aperfeiçoamento do Ensino Básico, o estabelecimento de parcerias com segmentos comunitários (aqui incluindo as administrações 
municipais) e a agilização na produção e socialização do conhecimento nas instituições participantes, pela articulação entre ensino, pesquisa e extensão.

Nesse sentido, o movimento tomou força e, em março de 1993, nove instituições de ensino superior comunitárias do Rio Grande do Sul firmaram um Protocolo de Ação Conjunta, constituindo o Consórcio das Universidades Comunitárias Gaúchas - COMUNG, com o intuito de viabilizar um processo integrativo que resultasse no fortalecimento individual das instituições e no conseqüente favorecimento da comunidade universitária rio-grandense e da sociedade gaúcha. Foram elas: Universidade de Caxias do Sul - UCS, Universidade de Santa Cruz do Sul - UNISC, Universidade de Passo Fundo - UPF, Universidade Católica de Pelotas - UCPel, Universidade Regional do Noroeste do Estado do Rio Grande do Sul - Unijuí, Universidade de Cruz Alta - UNICRUZ, Universidade Regional Integrada do Alto Uruguai e das Missões - URI, Universidade da Região da Campanha - URCAMP e Centro Universitário FEEVALE. Constituído oficialmente em 27 de abril de 1996, esse consórcio rege-se por seu Estatuto e por disposições legais pertinentes, sendo sua sede e foro jurídico a cidade de Porto Alegre.

As Universidades que formam o COMUNG representam uma verdadeira rede de educação, ciência e tecnologia, que abrange quase todos os municípios do interior do Estado do Rio Grande do Sul. No seu conjunto, as instituições do COMUNG congregam mais de 40 campi universitários, abrangem mais de 380 municípios em suas áreas de influência, e possuem em torno de 120 mil alunos de graduação e pós-graduação, constituindo-se, portanto, no maior sistema de educação superior em atuação no Rio Grande do Sul ${ }^{3}$. Conforme Nunes, Moretto e Rosa (SEMINÁRIO PAIUNG, 2003, p. 6), "as ações integradas e a cooperação interinstitucional são marcas características do COMUNG.”

Das catorze instituições integrantes da Associação Brasileira das Universidades Comunitárias - ABRUC, doze delas fazem parte do COMUNG. Além das instituições que fundaram esse consórcio, nos últimos anos, também passaram a integrá-lo o Centro Universitário UNIVATES, a Universidade do Vale do Rio dos Sinos - UNISINOS e a Pontifícia Universidade Católica do Rio Grande do Sul - PUCRS.

Desde sua constituição, o COMUNG possui os seguintes objetivos e linhas básicas de ação:

- Planejar e promover ações conjuntas, otimizando as relações internas, com as instituições públicas e com a sociedade;

3 Dados disponíveis no site http://www.comung.org.br 
- Assegurar maior força na defesa dos interesses educacionais dos seus participantes, através de negociações mais significativas no âmbito público em todas as esferas administrativas e da sociedade civil organizada;

- Alcançar maior representatividade perante organismos financiadores internacionais, pela capacidade de integração político-institucional;

- Proporcionar e operacionalizar convênios, acordos, protocolos com instituições e órgãos governamentais e privados, tanto nacionais como internacionais;

- Acentuar o trabalho de entrosamento com organismos públicos, em todos os níveis, e/ou privados, em especial na área de Ciência e Tecnologia, assegurando a presença ativa do Consórcio na implantação de Pólos Tecnológicos;

- Viabilizar a realização de eventos que respondam ao interesse do ensino superior e da pesquisa.

Verifica-se, pelo exposto, que o COMUNG é resultado de um movimento de articulação em busca da resistência ao anonimato das instituições de ensino superior comunitárias gaúchas frente ao conjunto de ações que vinham realizando e mantendo com as comunidades local e regional, quase sempre desde suas criações. Esse movimento em prol do COMUNG foi precursor, inclusive, de movimentos que originaram outras associações, como a própria ABRUC, que teve sua organização, em âmbito nacional, apenas em 1995, como já mencionado. Para Campis (SEMINÁRIO PAIUNG, 2003, p. 13), esse consórcio é

[...] fundamental para que possamos continuar construindo o futuro do ensino superior, especialmente no Rio Grande do Sul, na medida em que as nossas comunidades construíram, por meio de seu trabalho, do seu esforço, o ensino superior, já que não havia outra possibilidade de termos o ensino superior se não fosse pela própria vontade e determinação das nossas comunidades.

A implantação do COMUNG, também, teve origem das discussões e reuniões que as instituições que o fundaram realizavam em torno de outro programa: o Programa de Avaliação Institucional das Universidades Comunitárias Gaúchas - PAIUNG, melhor explicitado no texto a seguir. 


\section{Avaliação e Universidade Comunitária: o Sinaes e o Modelo Paiung}

Na década de 1980, os movimentos em favor da avaliação no Brasil aconteceram, principalmente, em razão das discussões acerca da necessidade de revisão da qualidade dos cursos de graduação, bem como da necessidade de revalorização dos títulos de pós-graduação que vinham sendo outorgados pelas IES, além de servir como prestação de contas dos recursos públicos que eram empregados nas universidades federais. (MENEGHEL; LAMAR, 2001, p. 20; DIAS SOBRINHO, 2003, p. 72; LIMA, 2005, p. 85)

Nessa década, percebe-se a existência de três momentos importantes ligados às questões da avaliação da Educação Superior. Primeiramente, em 1983, surge o Programa de Avaliação da Reforma Universitária - PARU, que, segundo Lima (2005, p. 85), pode ser considerada como "a primeira experiência abrangente de avaliação na educação superior brasileira”. Depois, em 1985, constata-se a criação do Grupo Executivo para a Reforma da Educação Superior - GERES, que produz um relatório centrado, basicamente, numa proposta de avaliação individual dos discentes, dos cursos superiores e das IES, vinculando os resultados dessas avaliações à distribuição de recursos financeiros por parte do Estado. Finalmente, em 1988, ocorre a promulgação da nova Constituição da República, onde, após uma série de discussões sobre o assunto, a avaliação é inserida em seu art. 209.

Todos esses momentos e discussões deram impulso para que, na década de 1990, a avaliação ganhasse maior visibilidade. Já no início dessa década, se dá a criação do Programa de Avaliação Institucional das Universidades Brasileiras - PAIUB, que foi oficialmente criado em dezembro de 1993, por meio do lançamento de um documento elaborado pela Secretaria da Educação Superior - SESu e pela Comissão Nacional de Avaliação das Universidades Brasileiras.

Além de ressaltar a importância de uma avaliação com caráter público, o PAIUB era um programa voluntário para as IES e contava, na sua origem, com financiamento do Governo Federal para a elaboração dos projetos de avaliação. Em um primeiro momento, esse financiamento ficou disponível apenas para as universidades públicas federais e estaduais, posteriormente se estendendo às comunitárias e às confessionais.

O PAIUB era baseado numa concepção que considerava tanto a avaliação formativa quanto a somativa. A primeira perspectiva é mais visível quando se verifica o caráter interno da avaliação, centrado em seu processo, objetivando 
a melhoria da qualidade institucional. Em relação à segunda perspectiva, percebe-se que, em muitos momentos, a avaliação também se dedica a quantificar ou determinar os diversos níveis da eficácia de seu objeto.

Outra característica fundamental do PAIUB era a concepção participativa da avaliação. Além da participação de toda comunidade acadêmica nos processos avaliativos, conclamava a participação da sociedade local e de ex-alunos para uma constante reflexão, autocrítica e co-responsabilidade no desenvolvimento institucional interno e externo, principalmente no que se refere à contribuição da instituição à sociedade em que está inserida. Nesse sentido, pode-se dizer que o PAIUB inspirou diretamente os processos avaliativos participativos, pois permitiram a construção de teias que venceram resistências locais e criaram uma cultura de avaliação que sobreviveu aos embates homogeneizadores. (LEITE, 2005, p. 65)

Do início da década de 1990 até o final de 1996, quando ocorreu a promulgação da atual LDBEN, pode-se dizer que a avaliação "não interferia no funcionamento das IES, embora as atividades de pesquisa fossem avaliadas pelas agências financiadoras e, a pós-graduação, pela Capes” (LIMA, 2005, p. 88). É bem verdade que a nova LDBEN deu início a uma concepção de avaliação vinculada aos processos de regulação e controle da educação superior. A partir de então, o Ministério da Educação passou a exercer, mais fortemente, a avaliação como controle e instrumentalização de suas políticas.

Isso fica bem evidenciado, inclusive, com a promulgação do Decreto $\mathrm{n}^{\circ}$ 2.026/96, que destacou, de forma ainda mais transparente, o papel do Ministério da Educação como órgão avaliador do ensino superior, por meio do Exame Nacional de Cursos - $\mathrm{ENC}^{4}$ (comumente conhecido como Provão), e da Avaliação das Condições de Oferta - ACO (que, mais tarde, passou a denominar-se Avaliação das Condições de Ensino - ACE).

Devido à adoção do Provão e da ACE, o PAIUB foi-se enfraquecendo e passou a exercer quase só a função da avaliação interna que cada instituição deveria desenvolver, de acordo com seus interesses e seus projetos desenvolvidos e encaminhados ao MEC. Nesse período, até o ano de 2003, acabou prevalecendo a avaliação externa, obrigatória, desenvolvida e controlada pelo

4 É importante destacar que a base para a criação do Exame Nacional de Cursos surgiu um ano antes, em 1995, por meio da Medida Provisória 1.018/95, referendada pela Lei $n^{\circ} 9.131 / 95$, que, no $\S 1^{\circ}$ do art. $3^{\circ}$, frisava que os procedimentos para as avaliações das instituições de ensino superior e de seus cursos incluiriam, a cada ano, exames nacionais, com base nos conteúdos mínimos estabelecidos para cada curso, previamente divulgados e destinados a aferir os conhecimentos e competências adquiridos pelos alunos em fase de conclusão dos cursos de graduação. 
Ministério da Educação, com a idéia de fiscalizar a qualidade de ensino superior oferecido por meio de seus instrumentos recém-criados.

Para Dias Sobrinho (2000), essa política de avaliação conduzida pelo Ministério da Educação, a partir de 1996, era fortemente marcada pela idéia de fiscalização e punição, devido à expansão desordenada de novas instituições privadas, oferta de ensino de baixa qualidade e com um grande foco no lucro.

Pelas normas definidas pelo Ministério da Educação, cursos que obtivessem conceitos “D” e "E” em três edições consecutivas do Provão ou CI (Condições Insuficientes) na Avaliação de Condições de Oferta/Ensino, deveriam passar por nova avaliação ou serem fechados, tendo em vista que esses não tinham alcançado os padrões mínimos de qualidade desejados. No entanto, não há conhecimento de cursos enquadrados nesses critérios que foram fechados pelo MEC durante todo o tempo em que essa sistemática esteve em vigência.

Tanto o Exame Nacional de Cursos quanto a Avaliação das Condições de Oferta/Ensino, permaneceram como instrumentos de avaliação, até o ano de 2003, quando assume o governo federal o atual Presidente da República, Luiz Inácio Lula da Silva. Dentre as propostas apresentadas pelo atual Presidente, quando da divulgação de seu Plano de Governo, no pleito eleitoral, existia a de $n^{\circ} 12$, a qual previa:

Rever o atual sistema de avaliação que inclui o Exame Nacional de Cursos - ENC ou Provão - e implantar um sistema nacional de avaliação institucional a partir, entre outras, da experiência do Programa de Avaliação Institucional das Universidades Brasileiras (PAIUB). (RISTOFF; GIOLO, 2006, p. 194)

Assim, logo no início do novo governo, foi criada a Comissão Especial de Avaliação da Educação Superior - CEA, cuja finalidade era a de "analisar, oferecer subsídios, fazer recomendações, propor critérios e estratégias para a reformulação dos processos e políticas de avaliação da Educação Superior e elaborar a revisão crítica dos seus instrumentos, metodologias e critérios utilizados". (BRASIL, 2003). Após quatro meses de estudo e debates com as comunidades acadêmica e científica, essa Comissão apresentou o documento "Sistema Nacional de Avaliação da Educação Superior - SINAES: Bases para uma Nova Proposta da Educação Superior”.

Em sua proposta original, o SINAES previa quatro instrumentos de avaliação:

a) auto-avaliação institucional, realizada de forma permanente e com apresentação trienal dos resultados; 
b) avaliação institucional externa, realizada por uma comissão de avaliadores, in loco, com o objetivo de avaliar a instituição como um todo;

c) Avaliação das Condições de Ensino, realizada também com o objetivo de avaliar um curso, nos casos em que uma comissão achar necessária uma verificação in loco;

d) Processo de Avaliação Integrada do Desenvolvimento Educacional e da Inovação da Área - PAIDEIA, que, em substituição ao Provão, estabelecia uma avaliação em quatro grandes áreas (Ciências Humanas, Exatas, Tecnológicas e Biológicas e da Saúde), abordando conhecimentos específicos do curso e outros de formação geral. Essa avaliação deveria ser aplicada aos alunos do final do primeiro ano e, também, do último ano do curso, selecionados por amostragem. (LIMA, 2005, p. 90)

Essa proposta trabalhava com base em fundamentos que previam uma avaliação de caráter tanto qualitativo, quanto quantitativo. Previa uma avaliação formativa, que buscasse uma análise e uma reflexão dos processos avaliativos e de aprendizagem, de modo que não permitisse o estabelecimento de rankings, como vinha acontecendo.

Outro ponto importante proposto pela CEA, quando da elaboração de seu documento, foi a criação da Comissão Nacional de Avaliação da Educação Superior - CONAES, como órgão coordenador e supervisor do SINAES.

As discussões acerca da proposta do SINAES levaram a algumas reformulações, o que gerou um segundo documento, intitulado "Sistema Nacional de Avaliação e Progresso do Ensino Superior - SINAPES", que foi apresentado à Comissão de Educação do Senado Federal pelo então Ministro da Educação, Cristovam Buarque, e, mais tarde, instituído por meio da Medida Provisória $n^{\circ} 147$, de 15 de dezembro de 2003.

Em resumo, o SINAPES propunha uma avaliação com maior ênfase no aspecto quantitativo, criando o Índice de Desenvolvimento do Ensino Superior - IDES, composto de quatro pilares:

a) o processo de ensino e a avaliação do corpo docente;

b) o processo de aprendizagem, com o Exame Nacional de Avaliação de Desempenho dos Estudantes - ENADE, em substituição ao provão e à sigla PAIDEIA; 
c) a capacidade institucional, utilizando-se de dados obtidos por meio da Avaliação das Condições de Ensino - ACE;

d) a responsabilidade do curso, verificando sua contribuição para a sociedade.

Essa nova proposta previa duas Comissões: a Comissão Nacional de Orientação da Avaliação - CONAV e a Comissão Nacional de Avaliação e Progresso do Ensino Superior - CONAPES. A primeira, deveria estabelecer as linhas acadêmicas da avaliação do ensino superior, enquanto que a segunda deveria deliberar sobre os critérios, métodos de análises e procedimentos de avaliação do SINAPES.

Com a reforma ministerial de 2004 e a nomeação de Tarso Genro como Ministro da Educação, outra proposta é apresentada ao Congresso, englobando aspectos e características das duas propostas anteriores. Assim, é sancionada a Lei no 10.861/2004, que cria o "Sistema Nacional de Avaliação da Educação Superior - SINAES”.

O SINAES, enquanto sistema integrado de avaliação, visa ao aprimoramento da avaliação das instituições de ensino superior, com caráter formativo, e, também ao aperfeiçoamento dos agentes da comunidade acadêmica e da IES como um todo. (BRASIL, 2004, p. 9)

Além de primar pelo caráter público da avaliação e pelo respeito à diversidade de instituições (universidades, centros universitários, faculdades, etc.), esse sistema busca uma integração entre instrumentos que abordem aspectos tanto quantitativos quanto qualitativos, dando ênfase a uma avaliação que privilegie três aspectos/olhares essenciais, valorizando a responsabilidade social da instituição, principalmente no que se refere à formação de seus alunos e à sua contribuição para a sociedade, a saber:

a) a avaliação institucional;

b) a avaliação de cursos;

c) a avaliação do desempenho discente.

A avaliação institucional, conhecida como "Avaliação das Instituições de Educação Superior - Avalies”, deve ser realizada por meio da auto-avaliação, coordenada por meio de uma Comissão Própria de Avaliação - CPA de cada IES, e da avaliação externa, realizada por uma comissão de avaliadores designada pelo INEP, segundo diretrizes da CONAES. 
A Avaliação dos Cursos de Graduação - ACG objetiva a verificação das condições de ensino oferecidas aos estudantes, por meio de um instrumento que contemplasse três dimensões:

a) A organização didático-pedagógica do curso;

b) O corpo social (docentes, discentes e técnico-administrativos);

c) A infra-estrutura.

O terceiro aspecto/olhar da avaliação estabelecida pelo SINAES é realizado por meio do Exame Nacional de Desempenho dos Estudantes - ENADE. Esse exame tem por objetivo avaliar o desempenho dos estudantes dos cursos de graduação em relação aos conteúdos previstos nas Diretrizes Curriculares Nacionais instituídas pelo Conselho Nacional de Educação, verificando, também, as competências e habilidades dos estudantes do primeiro e do último ano de cursos sugeridos pela CONAES, em relação à compreensão de assuntos de conhecimento geral, ligados às realidades brasileira e mundial e a outras áreas do conhecimento.

Enquanto sistema, não é possível analisar o SINAES com base em apenas um instrumento e/ou aspecto/olhar, dada a sua complexidade. O SINAES requer múltiplas análises, em momentos distintos, buscando-se compreender o complexo por meio da compreensão das partes de cada um de seus componentes, ou seja, cada um dos componentes é analisado conforme suas singularidades, mas, ao final do processo, esses devem ser unidos para a explicação do todo. (BRITO; LIMANA, 2005, p. 10)

É importante destacar que, com a implementação do SINAES, a avaliação não perdeu o seu caráter regulatório, que já havia sido estabelecido pela própria LDBEN. No entanto, mesmo com seu caráter regulatório, esse novo sistema, assim como previa o PAIUB, mantém as questões referentes à necessidade da participação da comunidade acadêmica nos processos de construção da autoavaliação institucional e dos cursos de uma IES. Isso fica bem evidenciado nas próprias Diretrizes da CONAES, que afirmam que:

Além de integração e articulação, é também central no SINAES a participação. Esta é uma exigência ética que convoca a todos os membros da comunidade acadêmica de educação superior, das instâncias institucionais, de setores governamentais ou da sociedade, a se envolverem nas ações avaliativas, respeitados os papéis e as competências científicas, profissionais, formais, políticas, administrativas e éticas das distintas categorias. (BRASIL, 2004, p. 5) 


\subsection{Programa de Avaliação Institucional das Universidades que Compõem o COMUNG - PAIUNG}

O PAIUNG foi criado em 1994 (enquanto projeto integrado, pois as primeiras discussões sobre o Programa começaram em 1993), articulando as ações relacionadas à avaliação institucional das Universidades que dele participam. Conforme informações disponíveis no site do Programa ${ }^{5}$, das doze instituições participantes do COMUNG, dez fazem parte do PAIUNG, a saber: Universidade de Caxias do Sul - UCS, Universidade de Santa Cruz do Sul - UNISC, Universidade de Passo Fundo - UPF, Universidade Católica de Pelotas - UCPel, Universidade Regional do Noroeste do Estado do Rio Grande do Sul - Unijuí, Universidade de Cruz Alta - UNICRUZ, Universidade Regional Integrada do Alto Uruguai e das Missões - URI, Universidade da Região da Campanha - URCAMP, Centro Universitário FEEVALE e Centro Universitário UNIVATES.

O objetivo principal desse Programa consiste em consolidar o processo sistemático e participativo de avaliação institucional, como estratégia essencial para o amadurecimento e o fortalecimento de cada instituição participante, dos mecanismos de articulação interinstitucional no âmbito do COMUNG e da contribuição das universidades comunitárias gaúchas e de sua representatividade no cenário acadêmico atual (SEMINÁRIO TEMÁTICO DO PAIUNG, 3, 2001, p. 11). Também se pode afirmar que, no PAIUNG, a avaliação deve nascer da vontade da comunidade e da própria instituição de se autoconhecer, buscando atingir seus objetivos básicos, a saber: a responsabilidade social e a formação de cidadãos. Além disso, a avaliação realizada por meio desse programa serve, também, para fortalecer a identidade e a missão das universidades comunitárias gaúchas.

Esse programa institucional se apoiou, em sua origem, nas características primordiais do PAIUB, principalmente no que se refere aos princípios, metodologias e procedimentos adotados, além de apresentar a concretização da relação da universidade com a comunidade. No entanto, esses mecanismos e orientações servem apenas como instrumentos norteadores, para que cada instituição participante do PAIUNG desenvolva suas próprias propostas.

A avaliação institucional estabelecida por esse Programa é realizada levando-se em consideração três níveis: o nacional, o regional e o individual de cada instituição, respeitando suas especificidades. Assim, pode-se dizer que os processos de avaliação desenvolvidos no PAIUNG servem para discutir as experiências e refletir sobre as práticas desenvolvidas pela instituição comunitária, com a idéia principal de se formar um projeto construído coletivamente.

5 http://www.paiung.tche.br 
Nesse sentido, essas instituições se reúnem em seminários temáticos, com o objetivo de discutir os resultados e relatórios parciais apresentados em cada etapa de avaliação, de forma que novas estratégicas sejam desencadeadas para as fases seguintes do processo.

Relacionado à referência metodológica utilizada pelo PAIUNG, assim como o extinto PAIUB (e, hoje, o SINAES), esse Programa procura desenvolver a avaliação por meio de dimensões articuladas, permeadas pela avaliação "da" comunidade e "com a" comunidade: a graduação, a pós-graduação, a pesquisa, a extensão e a gestão. Essas dimensões são avaliadas tendo como base as seguintes ações: motivação e organização, diagnóstico, avaliação interna, consolidação dos dados, avaliação externa, reconsolidação interna, priorização de ações/tomada de decisões e publicização dos resultados. (SEMINÁRIO TEMÁTICO DO PAIUNG, 3, 2001, p. 15-16)

Pode-se dizer, também, que o PAIUNG é marcado pela execução de fases / etapas. A primeira etapa, conhecida como PAIUNG I, aconteceu de 1994 a 1999 e teve como questões primordiais: o apoio financeiro por parte do governo (existente, inclusive, em razão do PAIUB); a avaliação centrada, basicamente, no ensino de graduação, de forma articulada com as demais dimensões da universidade; a busca pela concretização da identidade comunitária das instituições avaliadas; o desafio em se tornar a avaliação um processo contínuo de aperfeiçoamento institucional; a prestação de contas à sociedade daquilo que as instituições estavam realizando em seus âmbitos interno e externo.

A segunda etapa, conhecida como PAIUNG II, ocorreu entre 2000 e 2003, tendo como características básicas: o avanço metodológico na construção de um projeto integrado de avaliação; a articulação dos olhares “interno” (comunidade acadêmica) e "externo" (sociedade civil e consultores externos), a centralidade no projeto institucional para a construção dos projetos de avaliação específicos de cada instituição; a retomada das discussões referentes às concepções, aos objetivos e aos princípios da avaliação institucional.

A terceira etapa, o PAIUNG III, está acontecendo desde 2004, tendo como característica principal a adequação e atendimento à legislação e aos procedimentos definidos pelo Sistema Nacional de Avaliação da Educação Superior - SINAES.

\section{Concepção Comunitária e Avaliação Institucional das Universidades Filiadas ao Paiung}

Com o objetivo de conhecer, mais particularmente, suas concepções de instituição comunitária e, também, sua prática e experiência nas questões referentes 
à avaliação institucional, foram enviadas para as dez IES que fazem parte do PAIUNG três questões abertas, as quais foram respondidas pela Universidade Católica de Pelotas - UCPel, pela Universidade Regional do Noroeste do Estado do Rio Grande do Sul - Unijuí, pela Universidade de Santa Cruz do Sul - UNISC, pelo Centro Universitário UNIVATES e pela Universidade Regional Integrada do Alto Uruguai e das Missões - URI.

Em relação à primeira questão: Qual a concepção ou representação de "universidade comunitária” que orienta as políticas e práticas institucionais de sua universidade? $O$ que diferencia fundamentalmente uma universidade comunitária de outras IES privadas e públicas?, a Universidade Católica de Pelotas ressaltou que, de acordo com o seu Estatuto, ela é uma instituição de ensino de caráter particular, comunitária, filantrópica e confessional. Seguindo suas diretrizes internas, enquanto Universidade Comunitária, nascida de uma comunidade concreta que é a Igreja de Pelotas e marcada por uma vocação regional, a UCPel: 1) empreende as suas atividades sem finalidade lucrativa, antes revertendo seus eventuais excedentes financeiros na demanda orientada pelos objetivos da própria Instituição; 2) mantém íntima vinculação com a comunidade através dos seus programas de ensino, pesquisa e extensão com manifesto objetivo social. Para essa Universidade, a distinção fundamental de uma IES Comunitária relaciona-se ao comprometimento de suas ações aos interesses, aos problemas e aos anseios da comunidade onde está inserida.

Já a Unijuí, ao responder à primeira questão, frisou que o termo "comunitário" se efetiva a partir de uma postura de articulação com a comunidade, se expressando pelo compromisso social e pela inserção da Instituição na busca do desenvolvimento regional e das condições de vida da sociedade local e regional. Também justifica o termo relacionando-o ao poder mantenedor, destacando que a Unijuí é mantida por uma fundação filantrópica e sem fins lucrativos, que não tem dono; por isso sua função sustenta-se no caráter social, ou seja, servir à comunidade. São os princípios de comunitária, de participação, de diálogo e de regional que orientam as práticas da Unijuí, nas dimensões do ensino, da pesquisa, da extensão e da gestão.

Em se tratando das questões fundamentais que diferenciam uma universidade comunitária de outros tipos de instituições, as ações da Unijuí pautam-se por princípios de patrimônio público não estatal, pela participação da comunidade interna e externa na gestão e nos processos institucionais, pelo debate público, pela eleição de seus dirigentes, de seus colegiados superiores e de departamentos. A Unijuí ressalta que em sua história percebe-se um viés político, desde a sua constituição, que prima pelo debate democrático e pela exposição pública 
de idéias e de problemas locais e regionais, na busca de inovações. Sustenta-se, nessa postura de debate público, que a universidade comunitária constituiu-se e constitui-se, buscando, constantemente, alternativas para que os discursos das áreas da administração, do jurídico e do econômico não sejam os que ditam as regras na universidade, por cima dos valores acadêmicos. Nesse sentido, afirma que é necessário que se privilegie a interdisciplinaridade entre as áreas do conhecimento para que se construam alternativas, tanto nos seus aspectos financeiros, quanto pedagógicos, pelo diálogo entre as diferentes áreas do saber que integram a educação superior.

A UNISC, ao responder a primeira questão remeteu-se, inicialmente, a fatos históricos de sua constituição, frisando que as iniciativas da educação superior comunitária no Rio Grande do Sul começaram a partir de 1950, quando as comunidades criaram as primeiras associações pró-ensino. Essas associações tinham raízes na história da colonização e da organização social dos imigrantes e de seus descendentes no território gaúcho. Com esses fatos, afirmam, também, que as IES Comunitárias diferenciam-se das demais instituições porque têm uma origem enraizada nas suas comunidades, sendo suas mantenedoras criadas especialmente com a finalidade de geri-las, não estando subordinadas a qualquer interesse empresarial ou governamental. Alegam, ainda, que a atuação das universidades comunitárias não se limita ao âmbito municipal, sendo sua abrangência de caráter regional, cumprindo um papel de desenvolvimento em suas comunidades que o Estado não consegue suprir. Finaliza sua resposta afirmando que, enquanto universidade comunitária, preza o compromisso e a qualidade universitária que se expressam por meio de politicas de ensino, de pesquisa e de extensão, com a democracia que se expressa em eleições diretas para todos os cargos de gestão, com a comunidade e com a realidade regional.

Para o Centro Universitário UNIVATES, universidade comunitária é um modelo concebido historicamente pelas sociedades locais, pelo vínculo que as instituições educacionais apresentam com suas comunidades, ou seja, a educação era e continua sendo tratada como prioridade e, na falta ou retardamento de ações governamentais, as lideranças comunitárias se posicionaram na tomada de iniciativas para criarem a sua escola/universidade. Para esse Centro Universitário, o que diferencia uma instituição comunitária de outros tipos de instituição está relacionado ao seu poder instituidor e mantenedor, ou seja, tem como mantenedora uma Fundação e possui, como seu órgão máximo, uma Assembléia formada por representantes docentes, discentes e técnico-administrativos, além de membros da sociedade civil. 
Terminando a análise da primeira questão, a URI se manifestou no sentido de que a concepção de universidade comunitária que possui compreende uma instituição nascida no seio da comunidade civil, sem dono e sem fins lucrativos, totalmente voltada à prestação de serviços de interesse da população regional e ao seu bem-estar social. Para essa universidade, o que diferencia uma instituição comunitária de outras instituições privadas e públicas, reside essencialmente na sua missão que, no caso da URI, consiste em formar pessoal ético e competente, inserido na comunidade regional, capaz de construir conhecimento e promover a cultura e o intercâmbio, a fim de desenvolver a consciência coletiva na busca contínua da valorização e solidariedade humanas.

Em relação à segunda questão: "A avaliação institucional praticada em sua universidade é coerente com os princípios e objetivos dessa Instituição? A avaliação realizada pelo COMUNG-PAIUNG se distingue de outras avaliações das demais universidades? Quais as principais semelhanças e diferenças? E em relação com o SINAES?, a UCPel declarou que, inicialmente, é preciso reconhecer que as instituições filiadas ao COMUNG-PAIUNG possuem uma longa história de avaliações. No entanto, esse fato não caracteriza uma homogeneização dos processos avaliativos entre essas instituições, pois cada uma delas, resguardadas suas especificidades e particularidades, possui uma caminhada diferente. Para essa universidade, o que distingue as instituições do COMUNG-PAIUNG das demais instituições, em relação à avaliação, é a experiência e a conseqüente inclusão da cultura avaliativa entre suas comunidades.

Com relação ao SINAES, frisa que na UCPel, onde o caráter formativo já era subjacente à concepção avaliativa, valeu-se da Lei $n^{\circ}$ 10.861/2004 para institucionalizar na Universidade o que se tem chamado de "reciprocidade", ou seja, aproveitar os resultados da avaliação para aprimorar os campos investigados.

Para a Unijuí, a avaliação institucional é uma prática que se efetiva desde a sua criação como instituição de ensino superior. O caráter comunitário sempre exigiu a participação da comunidade, tanto interna quanto externa, na definição dos rumos da instituição. Assim, pode-se dizer que a avaliação e o planejamento são elementos essenciais no fazer universidade, pois avalia-se para planejar e planeja-se para avaliar. Com a implementação do SINAES, em 2004, essa concepção de avaliação "do todo pelo todo", vem reiterar os pressupostos da Unijuí.

Referente à distinção da avaliação realizada pelo COMUNG-PAIUNG da avaliação praticada pelas demais Universidades Brasileiras, bem como 
da avaliação proposta pelo SINAES, a Unijuí afirma que as instituições que integram o COMUNG-PAIUNG não tiveram dificuldades na compreensão $e$ implementação do SINAES, uma vez que já desenvolviam os seus processos de avaliação tendo como princípios uma avaliação permanente, como processo "do todo pelo todo".

Relacionadas às principais semelhanças da avaliação praticada entre instituições comunitárias, federais, estaduais e estritamente particulares, mencionam a exigência e a necessidade de se cumprir a Lei do SINAES. Quanto às diferenças, entendem que as instituições comunitárias, em sua maioria, têm na sua origem a missão de promover a formação com vistas ao desenvolvimento regional, tendo como princípios o envolvimento da comunidade interna e externa nos colegiados e processos decisórios.

A Unijuí finaliza sua resposta afirmando que o PAIUNG, enquanto programa de avaliação, tem um projeto comum de compromisso e de responsabilidade com o desenvolvimento regional e com a sociedade, a partir de características que lhe são peculiares.

A Universidade de Santa Cruz do Sul - UNISC fundamenta sua resposta relatando que pratica a avaliação de forma institucionalizada, por meio de um Programa próprio, desde o ano de 1994, que tem como um de seus princípios a avaliação como subsídio para o fortalecimento do modelo de universidade comunitária. Assim, a avaliação institucional assume um compromisso com a comunidade na medida em que tem por objetivo verificar o cumprimento da missão, da visão, da concepção e dos compromissos assumidos pela Universidade. Além disso, está expresso nos compromissos da Universidade que a qualidade universitária passa, em todas as suas dimensões, por um programa permanente de avaliação, cujo principal objetivo é subsidiar o planejamento e a tomada de decisões.

Para a UNISC, o grande diferencial da avaliação realizada pelas IES comunitárias é que ela não é entendida como um processo cuja única finalidade é cumprir uma determinação legal. Assim, afirma que a lacuna, em termos de diretrizes nacionais de auto-avaliação, verificada entre o enfraquecimento do PAIUB e a criação do SINAES não fez com que nenhuma dessas instituições abandonasse essa prática.

Em relação ao SINAES, a UNISC alega que este sistema é entendido pelas instituições comunitárias como um instrumento de melhoria da qualidade e de reconhecimento da relevância das atividades de cada uma e do conjunto de instituições educacionais brasileiras. Para essa Universidade, desde a primeira proposta desse novo Sistema, as instituições comunitárias o apoiaram e têm 
trabalhado no sentido de contribuir para o seu aperfeiçoamento e sua legitimidade perante a sociedade brasileira.

O Centro Universitário UNIVATES, ao responder a segunda questão, afirmou que suas atividades voltadas para a avaliação institucional se iniciaram na década de 1990, período em que a instituição se transformou em Centro Universitário. Naquela época, foram seguidas as orientações do PAIUB, pois, como Centro Universitário, a UNIVATES não integrou inicialmente o COMUNG-PAIUNG.

Referente aos seus processos avaliativos, o UNIVATES informou que o projeto atualmente existente apresenta coerência com sua missão, sua visão e seus princípios institucionais. Nesse sentido, a avaliação é concebida pela UNIVATES como um processo de construção e melhoria da qualidade de todas as ações desenvolvidas pela instituição, com a participação dos segmentos da comunidade academica e regional. A inclusão do UNIVATES no COMUNGPAIUNG, em 2005, veio a fortalecer o processo de avaliação que estavam desenvolvendo. Nesse sentido, os encontros e as reuniões que a instituição passou a integrar, a partir de então, permitem afirmar que houve um crescimento com a integração, o aperfeiçoando e a ampliação de suas ações.

Em relação ao SINAES, percebe-se que houve adequação à legislação, que prevê um trabalho mais centrado nas dez dimensões e que envolvem os três grandes eixos norteadores: Avaliação Institucional, Avaliação dos Cursos e a Avaliação do Desempenho dos Estudantes.

Terminando a análise da segunda questão, a Universidade Regional Integrada do Alto Uruguai e das Missões - URI ressaltou que a avaliação e a auto-avaliação buscam coerência entre a prática das mesmas e os princípios éticos que a norteiam.

Para a URI, a avaliação realizada pelo COMUNG-PAIUNG se distingue daquela praticada em outras universidades porque se volta às realidades internas e ao seu entorno, por praticarem linhas similares de ação no processo de auto-avaliação, de coleta, de compilação e de análise de dados, de tratamento e de divulgação dos resultados, além da transparência no diálogo com a comunidade. Relacionado ao SINAES, o processo de auto-avaliação tem seguido as suas orientações gerais e utilizado esse sistema para embasar as suas ações.

Tratando da terceira e última questão: Como e com qual intensidade se dá a participação da comunidade interna e externa no processo de avaliação institucional de sua universidade? Quais os resultados mais importantes desse processo?, a Universidade Católica de Pelotas - UCPel afirma que, além do levantamento de dados e manutenção de um site para atender à avaliação 
externa, aplica-se um instrumento de auto-avaliação e avaliação docente semestralmente, além de pesquisas de opinião para professores, estudantes, funcionários, egressos, comunidade geral e entidades parceiras, há cada três anos. Os resultados mais importantes de seu processo avaliativo foram: 1) a constituição do Grupo de Pesquisa em Pedagogia Institucional da UCPel, que vem sistematizando suas investigações por meio de artigos, de anais em congressos, de monografias e até uma tese de doutorado; 2) o Programa de Aperfeiçoamento Docente da UCPel, instituído com base em uma proposta da CPA; e 3) o site da CPA-UCPel, que serve para "radiografar" a Universidade diariamente, enfatizando outros resultados também importantes.

Em resposta à terceira questão, a Unijuí informou que a auto-avaliação é desenvolvida internamente pelos atores institucionais, nos departamentos, nos setores, na reitoria e no diretório dos estudantes. Nessa perspectiva, é papel da CPA: a motivação para que cada órgão se auto-avalie, o acompanhamento desse processo e a sua sistematização. $\mathrm{O}$ envolvimento dos atores / sujeitos institucionais acontece em seus próprios espaços e nos fóruns institucionais, respeitadas as especificidades, a estrutura e a organização de cada órgão.

ACPA da Unijuí também promove eventos com temas específicos de avaliação, em que todos os atores / sujeitos envolvidos são chamados ao debate. Podese dizer, no entanto, que a participação de todos os segmentos (professores, alunos, técnico-administrativos e de apoio e comunidade externa) acontece de forma tímida. Essa participação por representação, na visão da Unijuí, pode ser interpretada por diferentes fatores, tendo destaque a complexidade institucional, pela regionalização; ou seja, várias atividades acontecem concomitantemente, em espaços geográficos diferentes.

Cabe ressaltar, ainda, que a representação da comunidade externa se faz presente em todas as reuniões da CPA da Unijui e traz a visão desse segmento sobre a universidade. Para melhor visualização do que a comunidade externa pensa a respeito da Unijuí, foi desenvolvida uma pesquisa de opinião, buscando perceber o que a sociedade espera da universidade e como avalia a atuação dos profissionais formados por ela. Esse instrumento, com questões abertas, foi enviado às Prefeituras, Associações Comerciais e Industriais, Coordenadorias Regionais de Educação, escolas municipais, estaduais e particulares, empresas, entidades de classe e para egressos da Unijuí. Constatou-se, com isso, que $a$ participação destes segmentos também é muito restrita, fato comprovado pela devolução dos questionários.

$\mathrm{Na}$ ótica da auto-avaliação, enquanto processo permanente, e considerando a dinâmica de trabalho que se instaurou a partir do contexto das políticas de 
avaliação do ensino superior, por intermédio do SINAES, e pela forma como ocorre a auto-avaliação na Unijuí, entende-se como marco significativo, a constituição de um Programa de Pesquisa sobre Avaliação Institucional. Nesse Programa, cadastrado no CNPq, inserem-se vários projetos de pesquisadores da instituição versando sobre o tema. Para os representantes da CPA da Unijuí, essa também é uma forma de envolvimento da comunidade interna.

Por fim, a Unijuí afirma que, na fase atual, os departamentos e setores estão realizando a análise do Relatório de Auto-Avaliação sistematizado pela CPA, com o objetivo de qualificar os seus processos institucionais.

Para a UNISC, a comunidade interna sempre teve uma participação expressiva na avaliação, facilitada, especialmente, por uma gestão de característica descentralizada e democrática. As comissões de avaliação da UNISC contam com representação ativa de professores e de técnico-administrativos. Em relação aos estudantes, observa-se uma participação expressiva e comprometida nos processos do ENADE e da ACG - Avaliação dos Cursos de Graduação; porém, no que se refere à auto-avaliação, ainda existem fragilidades. Os discentes reconhecem, por exemplo, que a UNISC tem uma cultura forte em avaliação, mas a participação deles, por vezes, é limitada.

Para essa IES, a participação da comunidade externa foi uma novidade implantada pelo SINAES, quando surgiu a determinação de que as CPAs deveriam ter, em sua composição, representantes da sociedade civil organizada.

Tendo em vista que a UNISC já passou pelos três processos determinados pelo SINAES (ENADE, ACG e AVALIES), pode-se concluir que a participação das comunidades interna e externa nos processos de avaliação institucional tem determinado, em grande parte, os bons resultados obtidos pela Universidade. Nesse sentido, a UNISC cita, em especial, a Avaliação Institucional Externa, realizada pelo INEP, que serviu para que a comissão in loco comprovasse os compromissos assumidos pela Universidade na região em que atua e para que a comunidade acadêmica da UNISC confirmasse suas conviç̧ões sobre as políticas institucionais de ensino, de pesquisa, de extensão e de gestão.

O Centro Universitário UNIVATES, ao responder à terceira questão, alega que a participação dos segmentos envolvidos no processo de avaliação está aumentando conforme ela é desenvolvida. Esse processo perpassa todos os setores da Instituição, envolvendo os funcionários, os professores e os alunos. A IES também informou que, semestralmente, o processo de auto-avaliação abre a possibilidade de avaliar as ações docentes, os serviços e o clima de trabalho na Instituição. Alunos, professores e funcionários são os avaliadores/avaliados, 
ficando a comunidade externa para ações mais específicas (egressos, órgãos municipais e outras entidades regionais).

Como resultados mais importantes, destaca-se uma mobilização maior de toda a comunidade acadêmica, um maior aproveitamento dos resultados de cada processo, tanto para o planejamento como para a gestão da Universidade. Também se relata que, no final de 2006, foi concluído e aprovado o novo Programa de Avaliação Institucional - PAIUNI e, a partir dele, espera-se criar uma cultura avaliativa institucional e um maior e melhor aproveitamento dos resultados.

Finalizando a última questão, a URI manifestou-se no sentido de que, quanto à participação interna, até o presente momento, as expectativas têm sido superadas. Mesmo antes da existência do SINAES, o processo de auto-avaliação ocorria diretamente nos cursos, sendo implementado com o acompanhamento dos coordenadores. A comunidade externa também sempre participou, sendo que, atualmente, a sua participação tem maior intensidade, contando com instrumento próprio e periodicidade de coleta de dados.

Para essa IES, os resultados apresentados permitem redimensionar ações político-pedagógicas, estratégias, criação de novos cursos (tanto de graduação quanto de pós-graduação), além de propiciar um canal constante de comunicação entre a instituição e a comunidade interna e externa.

\section{Considerações Finais}

Nos últimos anos, verifica-se que, mesmo com a expansão neoliberal na educação, algumas instituições mantiveram-se fiéis aos princípios maiores da educação, reconhecendo o seu caráter público e não a tratando como simples mercadoria.

Essas instituições surgiram em locais onde o poder público se ausentou e a comunidade (em alguns casos, com a participação da igreja e outras congregações religiosas) se articulou para a criação de um tipo de instituição que não almejasse lucro com a educação, mas, sim, o oferecimento de uma educação de qualidade, para uma população carente desse tipo de instrução. Nasceram, assim, as Universidades Comunitárias.

Essa preocupação fica mais bem evidenciada ao analisarmos essas instituições quanto à sua missão e aos seus objetivos, quando, então, se constata a sua ligação com as comunidades local e regional, o compromisso com a educação e os resultados de suas práticas e de seus serviços vinculados ao ensino, à pesquisa e a extensão voltados para essas comunidades. São, pois, essas instituições 
de ensino superior, fortemente comprometidas com a responsabilidade social e com a formação de cidadãos críticos e reflexivos, e não só com a formação para o mercado de trabalho.

Hoje, as instituições comunitárias existem em doze estados brasileiros, estando mais fortemente desenvolvidas e caracterizadas como tais no Sul do país. Além de se articularem por meio de uma Associação Nacional, a ABRUC, essas instituições também se aglutinam no COMUNG, consórcio regional de caráter educacional e político que constitui, hoje, o maior sistema de educação superior em atuação no Rio Grande do Sul.

A avaliação institucional esteve presente nessas universidades comunitárias desde sua origem, como demonstrado no texto deste artigo. Nesse sentido, um dos pontos fortes do COMUNG é o PAIUNG, Programa Institucional de Avaliação que teve sua origem na época do PAIUB e que conta com a participação de quase todas as suas instituições afiliadas. Verifica-se que o PAIUNG tenta se consolidar como um importante instrumento político, no que se refere à avaliação institucional no país, e tem, nessa avaliação, um importante mecanismo de gestão acadêmica.

Para as instituições afiliadas ao COMUNG-PAIUNG, a avaliação é um processo contínuo de autoconhecimento e de autodesenvolvimento, que deve contar com a participação das comunidades interna e externa, e permitir a busca pelo aperfeiçoamento e pelo aprimoramento de atividades de ensino, de pesquisa, de extensão e de gestão de cada IES. É por meio da avaliação institucional, também, que essas instituições verificam, mais fortemente, se estão desempenhando o seu papel enquanto instituição de ensino superior e se estão, também, cumprindo a sua missão.

Ao consultar as instituições afiliadas ao COMUNG-PAIUNG, pôde-se observar que em relação à suas concepções, enquanto instituições comunitárias, e às suas diferenças em relação a outras universidades, as instituições comunitárias participantes desta pesquisa, em um sentido amplo, apresentam em comum a não subordinação a qualquer interesse empresarial ou à esfera governamental na sua mantença, além de uma íntima vinculação com a sociedade civil, entendendo a educação como um bem público, sem finalidade lucrativa. Também, entendem que suas atividades de ensino, de pesquisa e de extensão devem se articular, de forma que contribuam para o desenvolvimento regional e para a melhoria das condições de vida da comunidade local. Outra característica marcante dessas instituições é a democracia existente em sua gestão, contando com a participação das comunidades interna e externa em seus diversos órgãos colegiados e na tomada de decisões. 
Sobre a avaliação praticada por essas instituições, no que se refere à sua concepção, constata-se que ela é entendida como um processo de melhoria da qualidade de todas as ações desenvolvidas pela instituição, com a participação dos segmentos das comunidades acadêmica (interna) e regional (externa) - tendo em vista o próprio caráter comunitário - com ações voltadas à verificação do cumprimento da missão, da visão, dos objetivos e dos compromissos e princípios éticos por elas assumidos. Essa avaliação já possui uma experiência acumulada de alguns anos, criando, gradativamente, uma cultura avaliativa entre suas comunidades e contribuindo para a criação das políticas institucionais.

A distinção da avaliação praticada nessas instituições comunitárias em relação à praticada em outras, é, basicamente, apoiada no pressuposto de que ela se volta às realidades interna e externa. Também, não se entende a avaliação apenas como mecanismo de regulação, como uma obrigatoriedade imposta pelo governo, mas, sim, como um instrumento de emancipação e de efetiva participação para o crescimento institucional. Apresentam, ainda, como pontos em comum, a prática de linhas similares de ação, no processo de auto-avaliação, de coleta, compilação e análise de dados, de tratamento e de divulgação dos resultados, além da transparência nas discussões e diálogo com as comunidades interna e externa.

No que se refere ao SINAES, esse sistema não trouxe para as instituições comunitárias muita novidade em termos de prática de auto-avaliação institucional, pois todas elas já desenvolviam essa prática há algum tempo. Nesse sentido, essas instituições apenas adequaram seus instrumentos ao exigido pela Lei (como, por exemplo, a avaliação das dez dimensões e a adequação de suas CPAs), de forma a contribuir para o aperfeiçoamento e dar legitimidade a seus processos, o que é constatado, também, com a avaliação externa proposta por esse sistema.

Por fim, em relação à participação das comunidades interna e externa na avaliação institucional, bem como aos resultados mais importantes desse processo, verifica-se o esforço das instituições para o envolvimento de todos os seus setores e segmentos acadêmicos (docente, discente e técnico-administrativo) no processo avaliativo institucional, além de um esforço para o envolvimento da comunidade externa. Os resultados dessas práticas avaliativas auxiliam no desenvolvimento de ações político-pedagógicas redimensionadas, bem como em estratégias para o desenvolvimento institucional, além de proporcionar uma comunicação contínua da instituição com a comunidade.

Pode-se afirmar, portanto, que as instituições comunitárias gaúchas afiliadas ao COMUNG, apesar de se encontrarem em diferentes níveis de consolidação, 
têm buscado concretizar suas características enquanto instituições comunitárias. Além disso, buscam o fortalecimento de seus ideais voltados para as questões de responsabilidade social, tanto na formação de cidadãos (objetivo maior das universidades) quanto na identificação de problemas da comunidade e desenvolvimento regional. A avaliação, nesse sentido, tem papel fundamental, pois é o principal instrumento de autoconhecimento institucional, de interação com as comunidades local e regional, e de auxílio na busca de resultados mais concretos para o desenvolvimento institucional e da sociedade.

\section{Referências}

BITTAR, Mariluce. O ensino superior privado no Brasil e a formação do segmento das universidades comunitárias. Avaliação, Campinas; Sorocaba, v. 6, n. 2, p. 33-42, jun. 2001.

BRASIL. Constituição (1988). Constituição da República Federativa do Brasil. Brasília, DF: Senado, 1988.

BRASIL. Ministério da Educação. Lei n 9.394, de 20 de dezembro de 1996. Estabelece as diretrizes e bases da educação nacional. Diário Oficial da União, Brasília, DF, 23 dez. 1996.

BRASIL. Ministério da Educação. Secretaria de Educação Superior. Portaria $\mathrm{n}^{\mathrm{o}}$ 11, de 28 de abril de 2003. Institui Comissão Especial com a finalidade de analisar, oferecer subsídios, fazer recomendações, propor critérios e estratégias para a reformulação dos processos e políticas de avaliação do ensino superior e elaborar a revisão crítica dos seus instrumentos, metodologias e critérios utilizados. Diário Oficial da União, Brasília, DF, 30 abr. 2003.

BRASIL. Comissão Nacional para a Reformulação da Educação Superior. Uma nova política para a educação superior. Brasília, 1985. Relatório final.

BRASIL. Ministério da Educação. Comissão Especial de Avaliação da Educação Superior (CEA). Sistema Nacional de Avaliação da Educação Superior - SINAES: bases para uma nova proposta de avaliação da educação superior. Brasília, 2003. 
BRASIL. Ministério da Educação. Comissão Nacional de Avaliação da Educação Superior. Diretrizes para a avaliação da educação superior. Brasília, 2004. Disponível em: <http://www.abmes.org.br/Textos/Manuais/Conais_Sinaes/diretrizes_conaes.pdf $>$ Acesso em: 25 ago. 2007.

BRITO, Márcia Regina F. de; LIMANA, Amir. O modelo de avaliação dinâmica e o desenvolvimento de competências: algumas considerações a respeito do ENADE. Avaliação, Campinas; Sorocaba, v. 10, n. 2, p. 9-32, jun. 2005.

DIAS SOBRINHO, José. Avaliação da educação superior. Petrópolis, RJ: Vozes, 2000.

. Avaliação: políticas educacionais e reformas da educação superior. São Paulo: Cortez, 2003.

. Avaliação da educação superior, regulação e emancipação. In: DIAS SOBRINHO, José; RISTOFF, Dilvo I. (Orgs.). Avaliação e compromisso público: a educação superior em debate. Florianópolis: Insular, 2003.

FRANTZ, Walter; SILVA, Enio Waldir da. As funções sociais da universidade: o papel da extensão e a questão das comunitárias. Ijuí: Unijuí, 2002.

FRANTZ, Walter. O processo de construção de um novo modelo de universidade: a universidade comunitária. In: RISTOFF, Dilvo; SEVEGNANI, Palmira (Orgs.). Modelos institucionais de educação superior. Brasília: INEP, 2006.

LEITE, Denise. Avaliação institucional participativa e a universidade socialmente empreendedora. Avaliação, Campinas; Sorocaba, v. 10, n. 1, p. 51-70, mar. 2005.

LIMA, Marcos Antonio Martins. A avaliação no contexto histórico brasileiro recente da educação superior. Avaliação, Campinas; Sorocaba, v. 10, n. 2, p. 83-95, jun. 2005.

MENEGHEL, Stela M.; LAMAR, Adolfo Ramos. Avaliação como construção social: reflexões sobre as políticas de avaliação da educação no Brasil. Avaliação, Campinas; Sorocaba, v. 6, n. 4, p. 17-26, dez. 2001.

MOROSINI, Marília Costa (Org.). Enciclopédia de pedagogia universitária: glossário. Brasília: INEP, 2006. v. 2 
RISTOFF, Dilvo; GIOLO, Jaime. O SINAES como sistema. RBPG, Brasília, v. 3, n. 6, p. 193-213, dez. 2006. Disponível em: <http://www2.capes.gov.br/ rbpg/portal/conteudo/Est_Artigo2_n6.pdf>. Acesso em: 20 ago. 2007.

SEMINÁRIO TEMÁTICO DO PAIUNG, 3, 2001, Santa Cruz do Sul, RS. Anais: avaliação institucional nas universidades face às políticas públicas. Organização: Ana Karin Nunes; Marcos Moura Baptista dos Santos. Santa Cruz do Sul, RS: EDUNISC, 2002. 112p. Disponível em: $<$ http://www.paiung.tche. br/ download/anaisIII.pdf>. Acesso em: 04 abr. 2007.

SEMINÁRIO PAIUNG, 2003, Ijuí, RS. Anais: uma década de avaliação institucional integrada. Oganizadores: Ana Karin Nunes; Cleide Fátima Moretto; Magna Stella Cargnetti Dalla Rosa. Ijuí, RS: [s. n.], 2003. 95p. Disponível em: $<$ http://www.paiung.tche.br/download/anais.pdf $>$. Acesso em: 04 abr. 2007.

VANNUCCHI, Aldo. A universidade comunitária. São Paulo: Loyola, 2004. 